\title{
Glucose Levels and Risk of Dementia
}

\author{
Paul K. Crane, M.D., M.P.H., Rod Walker, M.S., Rebecca A. Hubbard, Ph.D., Ge Li, M.D., \\ Ph.D., David M. Nathan, M.D., Hui Zheng, Ph.D., Sebastien Haneuse, Ph.D., Suzanne Craft, \\ Ph.D., Thomas J. Montine, M.D., Ph.D., Steven E. Kahn, M.B., Ch.B., Wayne McCormick, \\ M.D., M.P.H., Susan M. McCurry, Ph.D., James D. Bowen, M.D., and Eric B. Larson, M.D., \\ M.P.H. \\ Departments of Medicine (P.K.C., W.M., E.B.L.), Psychiatry and Behavioral Sciences (G.L.), \\ Pathology (T.J.M.), and Psychosocial and Community Health (S.M.M.), University of Washington; \\ the Group Health Research Institute (R.W., R.A.H., E.B.L.); the Department of Medicine, VA \\ Puget Sound Health Care System and University of Washington (S.E.K.); and the Swedish \\ Neuroscience Institute (J.D.B.) - all in Seattle; the Diabetes Center and Department of Medicine \\ (D.M.N.) and the Biostatistics Center (H.Z.), Massachusetts General Hospital and Harvard \\ Medical School; and the Department of Biostatistics, Harvard School of Public Health (S.H.) - all \\ in Boston; and the Department of Internal Medicine, Wake Forest School of Medicine, Winston- \\ Salem, NC (S.C.)
}

\begin{abstract}
BACKGROUND—Diabetes is a risk factor for dementia. It is unknown whether higher glucose levels increase the risk of dementia in people without diabetes.

METHODS-We used 35,264 clinical measurements of glucose levels and 10,208 measurements of glycated hemoglobin levels from 2067 participants without dementia to examine the relationship between glucose levels and the risk of dementia. Participants were from the Adult Changes in Thought study and included 839 men and 1228 women whose mean age at baseline was 76 years; 232 participants had diabetes, and 1835 did not. We fit Cox regression models, stratified according to diabetes status and adjusted for age, sex, study cohort, educational level, level of exercise, blood pressure, and status with respect to coronary and cerebrovascular diseases, atrial fibrillation, smoking, and treatment for hypertension.
\end{abstract}

RESULTS-During a median follow-up of 6.8 years, dementia developed in 524 participants (74 with diabetes and 450 without). Among participants without diabetes, higher average glucose levels within the preceding 5 years were related to an increased risk of dementia $(P=0.01)$; with a glucose level of $115 \mathrm{mg}$ per deciliter (6.4 mmol per liter) as compared with $100 \mathrm{mg}$ per deciliter (5.5 mmol per liter), the adjusted hazard ratio for dementia was 1.18 (95\% confidence interval [CI], 1.04 to 1.33). Among participants with diabetes, higher average glucose levels were also related to an increased risk of dementia $(\mathrm{P}=0.002)$; with a glucose level of $190 \mathrm{mg}$ per deciliter (10.5 mmol per liter) as compared with $160 \mathrm{mg}$ per deciliter ( $8.9 \mathrm{mmol}$ per liter), the adjusted hazard ratio was 1.40 (95\% CI, 1.12 to 1.76$)$.

CONCLUSIONS-Our results suggest that higher glucose levels may be a risk factor for dementia, even among persons without diabetes. (Funded by the National Institutes of Health.)

Copyright @ 2013 Massachusetts Medical Society.

Address reprint requests to: Dr. Crane at Box 359780, Harborview Medical Center, 325 Ninth Ave., Seattle, WA 98104, or at pcrane@uw.edu.

Disclosure forms provided by the authors are available with the full text of this article at NEJM.org. 
With the aging of the population, dementia has become a major threat to public health worldwide. ${ }^{1}$ The rate of obesity is also increasing, with a parallel increase in the rate of diabetes. $^{2}$ The results of studies assessing the association between obesity or diabetes and the risk of dementia have been mixed. ${ }^{3,4}$ It is imperative to understand the potential consequences of the obesity and diabetes epidemics for the incidence of dementia. ${ }^{5}$ Any effects that obesity has on the risk of dementia are likely to include effects on metabolism. We evaluated extensive longitudinal clinical data from a prospective cohort with researchquality case ascertainment to test the hypothesis that glucose levels are associated with the risk of dementia.

\section{METHODS \\ PARTICIPANTS}

The Adult Changes in Thought (ACT) study ${ }^{6}$ initially included 2581 randomly selected dementia-free members of the Group Health Cooperative (hereafter referred to as Group Health), a health care system in Washington State. Participants had to be 65 years of age or older at the time of e4nrollment, which occurred from 1994 through 1996. An additional 811 participants were enrolled between 2000 and 2002. Participants were invited to return at 2year intervals for the purpose of identifying incident cases of dementia. The sample for the current study was limited to 2067 participants who had at least one follow-up visit, had been enrolled in Group Health for at least 5 years before study entry, and had at least five measurements of glucose or glycated hemoglobin (measured as hemoglobin $\mathrm{A}_{1 \mathrm{C}}$ or as total glycated hemoglobin, with the latter measurement reflecting an older hemoglobin assay) over the course of 2 or more years before study entry. The demographic characteristics of the ACT study participants who were included in the current study and those who were excluded were similar, although several clinical characteristics were more common among participants in the current study (see Table S1 in the Supplementary Appendix, available with the full text of this article at NEJM.org).

\section{STUDY OVERSIGHT}

The study procedures were approved by the institutional review boards of Group Health and the University of Washington, and participants provided written informed consent. The first three authors vouch for the accuracy of the study and the completeness of the data and analysis. Author responsibilities are discussed in the Methods S7 section in the Supplementary Appendix.

\section{IDENTIFICATION OF DEMENTIA}

Study participants were assessed for dementia every 2 years with the use of the Cognitive Abilities Screening Instrument, for which scores range from 0 to 100 and higher scores indicate better cognitive functioning. ${ }^{7}$ Patients with scores of 85 or less underwent further clinical and psychometric evaluation, including a battery of neuropsychological tests (see the Methods S1 section in the Supplementary Appendix). The results of these evaluations and laboratory testing and imaging records were then reviewed in a consensus conference. Diagnoses of dementia ${ }^{8}$ and of probable or possible Alzheimer's disease ${ }^{9}$ were made on the basis of research criteria. Dementia-free participants continued with scheduled follow-up visits. The incidence date for dementia was recorded as the halfway point between the study visit at which dementia was diagnosed and the previous visit. ${ }^{6}$

\section{RISK FACTORS ASSESSED}

Glucose Levels-Clinical data, including measurements of fasting glucose, random measurements of glucose, and measurements of glycated hemoglobin, were captured as 
computerized laboratory data from 1988 onward. We transformed values for total glycated hemoglobin to hemoglobin $A_{1 C}$ values using this formula: hemoglobin $A_{1 C}=(0.6 \times$ total glycated hemoglobin) +1.7. We then transformed the calculated hemoglobin $\mathrm{A}_{1 \mathrm{C}}$ values to daily average glucose values with this formula: daily average glucose $=(28.7 \times$ hemoglobin $\left.\mathrm{A}_{1 \mathrm{C}}\right)$ - 46.7. ${ }^{10} \mathrm{We}$ combined the recorded glucose values and daily average glucose values derived from glycated hemoglobin values using a hierarchical Bayesian framework (see the Methods S2 section in the Supplementary Appendix) to compute a time-varying estimate of the average glucose level for each participant. This approach creates an estimate of glucose level, weighted by the precision of the measures for glucose and glycated hemoglobin and stabilized with the use of a shrinkage factor to account for the instability of the estimation for participants with relatively few observations. We computed average glucose levels for each participant at study baseline and subsequently in 5-year rolling windows. Our approach to measurement was closely correlated with a simpler way of estimating glucose exposure (see the Methods S3 section and Fig. S6 in the Supplementary Appendix). The analysis included data from study participants for all time frames in which at least one measurement of glucose or glycated hemoglobin was available. Our secondary analyses explicitly considered more recent exposure (average glucose level in the preceding 5 years) as compared with more distant exposure (average glucose level in the period between 5 and 8 years earlier).

Diabetes-We classified participants as having treated diabetes on the basis of diabetesrelated medication data from Group Health pharmacy records (Table S2 in the Supplementary Appendix). At least two filled prescriptions per year were required for the classification, with the onset date for treated diabetes defined as the date when the second prescription was filled. Once a participant was classified as having treated diabetes, the classification was retained for the remainder of the study.

Apolipoprotein E Genotype-Data on apolipoprotein E (APOE) genotype were available for 1818 participants (88\%). APOE status was determined with the use of published methods ${ }^{11,12}$ and categorized as the presence or absence of any $\varepsilon 4$ alleles.

Other Risk Factors-Risk factors with the potential to confound the relation between glucose levels and dementia were defined with the use of ACT study and Group Health data sources (see the Methods S4 section in the Supplementary Appendix). Exercise level was assessed with the use of questions about types of physical activity and the number of times each was performed in a week. These numbers were totaled, and those who exercised 3 or more days per week were categorized as having regular exercise, as previously reported. ${ }^{13}$ At each study visit, a research staff member administered a questionnaire that asked participants about their smoking status and whether a doctor had told them they had coronary artery disease, cerebrovascular disease, or hypertension. Blood pressure, measured while the participant was seated, was determined as the average of two measurements on the left arm, with a 5-minute rest period between measurements. Atrial fibrillation was determined with the use of codes 427.3, 427.31, and 427.32 from the International Classification of Diseases, 9th Revision, in accordance with procedures at Group Health. Treatment for hypertension was determined on the basis of Group Health pharmacy data (Table S3 in the Supplementary Appendix).

\section{STATISTICAL ANALYSIS}

We used stratified Cox regression models with empirical standard errors to examine the relation between glucose level and incidence of dementia. Age was used as the time axis. Stratification was based on status with respect to diabetes and cerebrovascular disease, which allowed for different baseline hazard functions across these strata in the estimation of 
model parameters. We controlled for age at study entry, study cohort, sex, educational level, exercise level, blood pressure, and status with respect to coronary artery disease, atrial fibrillation, smoking, and treatment for hypertension.

Glucose levels were incorporated in models with the use of natural cubic splines ${ }^{14}$ (see the Methods S8 section in the Supplementary Appendix) to allow for a nonlinear association between glycemia and risk of dementia as measured by the log hazard. Separate splines were used in accordance with diabetes status. The statistical significance (at the 0.05 level) of the association between glycemia and risk of dementia was estimated with the use of two-sided Wald tests of the composite hypotheses that all model parameters associated with the splines were equal to 0 (omnibus tests; $a=0.05$ ). We assessed the proportional hazards of covariate effects by testing for interactions with (log) time and plotting Schoenfeld residuals. ${ }^{15}$ All statistical analyses were performed with the use of SAS software, version 9.2 (SAS Institute), and R, version 2.15.1 (R Foundation for Statistical Computing).

We performed several sensitivity analyses, testing for interactions with glucose levels according to sex and age at study entry, investigating clinical data from participants whose data were particularly influential on model results, contracting or expanding the window for calculating the average glucose level ( 2 or 8 years rather than 5 years), adjusting for the presence of one or more $A P O E \& 4$ alleles, changing the parameters of the prior distribution within the Bayesian framework for exposure computation (see the Methods S5 section in the Supplementary Appendix), and making additional modifications to our glucose exposure model to account for prandial status when that was indicated (see the Methods S6 section in the Supplementary Appendix).

\section{RESULTS \\ BASELINE CHARACTERISTICS}

The baseline characteristics of the 2067 study participants are presented in Table 1 . There were 35,264 values available for fasting and random glucose levels and 10,208 values available for glycated hemoglobin levels (total glycated hemoglobin or hemoglobin $\mathrm{A}_{1 \mathrm{C}}$ ). During the 5 years preceding study enrollment, the median glucose level for participants without diabetes was $101 \mathrm{mg}$ per deciliter (interquartile range, 96 to 108 [5.6 mmol per liter; interquartile range, 5.3 to 6.0]), and the median level for those with diabetes was $175 \mathrm{mg}$ per deciliter (interquartile range, 153 to 198 [9.7 mmol per liter; interquartile range, 8.5 to 11.0]). Distributions of glucose levels throughout the study period are summarized in Table S4 and Figure S1 in the Supplementary Appendix.

\section{DEMENTIA, ALZHEIMER'S DISEASE, AND GLYCEMIA}

Over a median follow-up period of 6.8 years, dementia developed in 524 of the 2067 participants (25.4\%), including 450 of the 1724 participants who did not have diabetes at the end of follow-up (26.1\%) and 74 of the 343 participants who had diabetes at the end of follow-up (21.6\%). A total of 403 participants (19.5\%) had probable or possible Alzheimer's disease at the end of follow-up, $55(2.7 \%)$ had dementia from vascular disease, and 66 (3.2\%) had dementia from other causes (Table S5 in the Supplementary Appendix).

Associations between average glucose levels in the preceding 5 years and the development of dementia are shown in Table 2 and Figure 1. Among participants without diabetes, the risk of dementia increased with increasing glucose levels $(P=0.01$ for the omnibus test). For an average glucose level of $115 \mathrm{mg}$ per deciliter (6.4 mmol per liter), as compared with 100 $\mathrm{mg}$ per deciliter (5.5 mmol per liter), the adjusted hazard ratio for dementia was 1.18 (95\% confidence interval $[\mathrm{CI}], 1.04$ to 1.33 ). Among participants with diabetes, those with the 
highest levels of glucose had an increased risk of dementia $(\mathrm{P}=0.002)$. For an average glucose level of $190 \mathrm{mg}$ per deciliter (10.5 mmol per liter), as compared with $160 \mathrm{mg}$ per deciliter ( $8.9 \mathrm{mmol}$ per liter), the adjusted hazard ratio for dementia was 1.40 (95\% CI, 1.12 to 1.76$)$.

Table 3 shows the results of analyses of the risk of dementia associated with glucose levels averaged over the preceding 5 years or the period between 5 and 8 years earlier. Average glucose levels were highly correlated for the two time periods $(r=0.85)$. Including glucose levels for both periods in regression models resulted in somewhat attenuated estimates of associations between more recent elevations in glucose levels and risk of dementia.

\section{SENSITIVITY ANALYSES}

There was no evidence of effect modification according to sex for participants without diabetes $(\mathrm{P}=0.86$ for interaction) or for participants with diabetes $(\mathrm{P}=0.72$ for interaction). Similarly, there was no evidence of effect modification according to age at study entry among participants without diabetes $(\mathrm{P}=0.84)$. However, there was a suggestion of possible effect modification according to age at study entry among participants with diabetes, but the effect was not significant $(\mathrm{P}=0.13)$. We estimated the hazard ratios for study entry at 70 to 78 years of age for participants with diabetes (Fig. S2 in the Supplementary Appendix). An increased risk associated with both higher and lower glucose levels appeared to be especially prominent among participants who were older at study entry.

Among people without diabetes, no individual participant had data that had a particularly marked influence on model parameter estimates (see the Results S1 section and Fig. S3 in the Supplementary Appendix). Some people with diabetes did have data that had a marked influence on model parameter estimates, and we reviewed their medical records. We repeated our primary analyses after excluding data from one participant with acromegaly (Fig. S4 in the Supplementary Appendix) and after excluding data from that participant and two other participants, each of whom had an atypical natural history of type 2 diabetes (Fig. S5 in the Supplementary Appendix). The exclusion of these data resulted in the near elimination of the suggestion of elevated risk at the lowest glucose levels.

Additional adjustment for the APOE genotype did not change our findings (Table S6 in the Supplementary Appendix). Point estimates were similar when 2-year windows of glucose exposure were used rather than 5-year windows, although the risk of dementia was significant only for participants with diabetes when the 2-year window of glucose exposure was used (Table S7 in the Supplementary Appendix). Results were similar when exposure was estimated assuming more dispersed or less dispersed prior distributions for glucose and hemoglobin $A_{1 C}$ (Table S8 in the Supplementary Appendix). Results were similar when we accounted for the differences between fasting and random glucose levels (Table S9 in the Supplementary Appendix).

\section{DISCUSSION}

In this prospective, community-based cohort study, we found that higher glucose levels were associated with an increased risk of dementia in populations without and with diabetes. The findings were consistent across a variety of sensitivity analyses. These data suggest that higher levels of glucose may have deleterious effects on the aging brain. Our findings underscore the potential consequences of temporal trends in obesity and diabetes ${ }^{5}$ and suggest the need for interventions that reduce glucose levels.

Most studies that have investigated associations between glucose metabolism and the risk of dementia have focused on diabetes itself, and they have yielded inconsistent results. ${ }^{4}$ Other 
studies have measured levels of glycated hemoglobin ${ }^{16-19}$ or assessed the results of glucose tolerance tests. ${ }^{20-22}$ Many of these studies have shown relationships between elevated levels of glycated hemoglobin or postprandial (but not fasting) glucose levels and dementia-related outcomes, such as changes in hippocampal volume on neuroimaging or rates of cognitive decline. To our knowledge, no prior study has evaluated glucose levels as a time-varying phenomenon. Most of the previous studies used categorical exposure variables, such as the presence or absence of diabetes or normal versus impaired glucose tolerance.

In contrast, we used a hierarchical Bayesian model to develop a time-varying estimate of glucose levels (see the Methods S2 section in the Supplementary Appendix). This approach enabled us to incorporate clinically obtained measurements of random and fasting blood glucose and glycated hemoglobin in a single composite estimate of glucose exposure. The extensive clinical laboratory data available and the long-term follow-up of the cohort, in which there were hundreds of cases of dementia, afforded us the opportunity to evaluate the hazards associated with glucose levels using a spline model, which allowed us to evaluate risk across the entire spectrum of observed glucose levels. We found a monotonically increasing association between the glucose level and the risk of dementia among people without diabetes, which suggests that any incremental increase in glucose levels is associated with an increased risk of dementia. We found the same relationship between glycemia and risk of dementia among people with diabetes at the higher end of the range of glucose levels. We also found an inverse association between glucose level and risk of dementia among people with diabetes who had relatively low levels of glucose, although this association appeared to be driven by glucose levels in three participants with atypical courses of type 2 diabetes. Our findings were consistent across many sensitivity analyses, reinforcing our confidence in their reliability.

Higher glucose levels may contribute to an increased risk of dementia through several potential mechanisms, including acute and chronic hyperglycemia and insulin resistance ${ }^{23}$ and increased microvascular disease of the central nervous system. ${ }^{24-28}$ Although the development of dementia in people with diabetes could have led to a deterioration in selfcare, which in turn may have led to increased glucose levels, the similar relationship between glycemia and dementia in people without diabetes suggests a different causal relationship. The underlying mechanisms of the association between elevated glucose levels and dementia need to be clarified in future studies.

There are several causes of dementia, including Alzheimer's disease, vascular disease, Lewy-body disease, and combinations of these disorders. ${ }^{29}$ It is difficult to discriminate reliably among these causes, so we chose to focus this assessment on overall dementia.

The strengths of this study include the prospective community-based design, the large sample with minimal attrition, access to extensive clinical laboratory and medical records, prospective ascertainment of cases of dementia with widely used research criteria, and careful sensitivity analyses. Several limitations should be acknowledged. The possibility of confounding by unmeasured or unknown factors cannot be excluded. We were limited to available clinical laboratory measurements obtained at irregular intervals for estimates of glucose levels. Measurements of glucose and glycated hemoglobin were numerous, with an average of 17 measurements of blood glucose and 5 measurements of glycated hemoglobin available per person. We noted large differences in glycemia between people with and those without diabetes. We stratified our analyses according to diabetes status, which was determined on the basis of whether a person was receiving diabetes-related medications. Diabetes was almost certainly present for several years before the initial prescription of such medications, which means that some of the higher glucose values observed among people who were classified as not having diabetes probably reflected diabetes that had not yet been 
treated with diabetes-related medications. We found that increased risk was associated with higher glucose levels even at the lowest end of the glucose spectrum among people who had not received a diagnosis of diabetes, for whom increased risk was not likely to be a result of undiagnosed diabetes. Our results may not be generalizable to other ethnic groups. Many of our covariates were obtained by self-report.

In conclusion, our data provided evidence that higher glucose levels are associated with an increased risk of dementia.

\section{Supplementary Material}

Refer to Web version on PubMed Central for supplementary material.

\section{Acknowledgments}

Supported by a grant (U01 AG 06781, to Dr. Larson) from the National Institutes of Health.

\section{References}

1. Reitz C, Brayne C, Mayeux R. Epidemiology of Alzheimer disease. Nat Rev Neurol. 2011; 7:13752. [PubMed: 21304480]

2. Lam DW, LeRoith D. The worldwide diabetes epidemic. Curr Opin Endocrinol Diabetes Obes. 2012; 19:93-6. [PubMed: 22262000]

3. Gorelick PB, Scuteri A, Black SE, et al. Vascular contributions to cognitive impairment and dementia: a statement for healthcare professionals from the American Heart Association/American Stroke Association. Stroke. 2011; 42:2672-713. [PubMed: 21778438]

4. Kloppenborg RP, van den Berg E, Kappelle LJ, Biessels GJ. Diabetes and other vascular risk factors for dementia: which factor matters most? A systematic review. Eur J Pharmacol. 2008; 585:97-108. [PubMed: 18395201]

5. Arterburn DE, Crane PK, Sullivan SD. The coming epidemic of obesity in elderly Americans. J Am Geriatr Soc. 2004; 52:1907-12. [PubMed: 15507070]

6. Kukull WA, Higdon R, Bowen JD, et al. Dementia and Alzheimer disease incidence: a prospective cohort study. Arch Neurol. 2002; 59:1737-46. [PubMed: 12433261]

7. Teng EL, Hasegawa K, Homma A, et al. The Cognitive Abilities Screening Instrument (CASI): a practical test for cross-cultural epidemiological studies of dementia. Int Psychogeriatr. 1994; 6:4558. [PubMed: 8054493]

8. Diagnostic and statistical manual of mental disorders. 4. Washington, DC: American Psychiatric Association; 1994.

9. McKhann G, Drachman D, Folstein M, Katzman R, Price D, Stadlan EM. Clinical diagnosis of Alzheimer's disease: report of the NINCDS-ADRDA Work Group under the auspices of Department of Health and Human Services Task Force on Alzheimer's Disease. Neurology. 1984; 34:939-44. [PubMed: 6610841]

10. Nathan DM, Kuenen J, Borg R, Zheng H, Schoenfeld D, Heine RJ. Translating the A1C assay into estimated average glucose values. Diabetes Care. 2008; 31:1473-8. Erratum, Diabetes Care 2009;32:207. [PubMed: 18540046]

11. Hixson JE, Vernier DT. Restriction isotyping of human apolipoprotein E by gene amplification and cleavage with HhaI. J Lipid Res. 1990; 31:545-8. [PubMed: 2341813]

12. Emi M, Wu LL, Robertson MA, et al. Genotyping and sequence analysis of apolipoprotein $\mathrm{E}$ isoforms. Genomics. 1988; 3:373-9. [PubMed: 3243553]

13. Larson EB, Wang L, Bowen JD, et al. Exercise is associated with reduced risk for incident dementia among persons 65 years of age and older. Ann Intern Med. 2006; 144:73-81. [PubMed: 16418406]

14. Hastie, T.; Tibshirani, RJ.; Freedman, J. Elements of statistical learning. New York: Springer; 2001. 
15. Kalbfleisch, JD.; Prentice, RL. Statistical analysis of failure time data. 2. Hoboken, NJ: John Wiley; 2002.

16. Yaffe K, Blackwell T, Whitmer RA, Krueger K, Barrett Connor E. Glycosylated hemoglobin level and development of mild cognitive impairment or dementia in older women. J Nutr Health Aging. 2006; 10:293-5. [PubMed: 16886099]

17. Ravona-Springer R, Moshier E, Schmeidler J, et al. Changes in glycemic control are associated with changes in cognition in non-diabetic elderly. J Alzheimers Dis. 2012; 30:299-309. [PubMed: 22426020]

18. Christman AL, Matsushita K, Gottesman RF, et al. Glycated haemoglobin and cognitive decline: the Atherosclerosis Risk in Communities (ARIC) study. Diabetologia. 2011; 54:1645-52. [PubMed: 21360189]

19. Enzinger C, Fazekas F, Matthews PM, et al. Risk factors for progression of brain atrophy in aging: six-year follow-up of normal subjects. Neurology. 2005; 64:1704-11. [PubMed: 15911795]

20. Ohara T, Doi Y, Ninomiya T, et al. Glucose tolerance status and risk of dementia in the community: the Hisayama study. Neurology. 2011; 77:1126-34. [PubMed: 21931106]

21. van den Berg E, de Craen AJ, Biessels GJ, Gussekloo J, Westendorp RG. The impact of diabetes mellitus on cognitive decline in the oldest of the old: a prospective population-based study. Diabetologia. 2006; 49:2015-23. [PubMed: 16804671]

22. Rönnemaa E, Zethelius B, Sundelöf J, et al. Glucose metabolism and the risk of Alzheimer's disease and dementia: a population-based 12 year follow-up study in 71-year-old men. Diabetologia. 2009; 52:1504-10. [PubMed: 19455303]

23. Strachan MW. RD Lawrence Lecture 2010: the brain as a target organ in Type 2 diabetes: exploring the links with cognitive impairment and dementia. Diabet Med. 2011; 28:141-7. [PubMed: 21219420]

24. Pandini G, Pace V, Copani A, Squatrito S, Milardi D, Vigneri R. Insulin has multiple antiamyloidogenic effects on human neuronal cells. Endocrinology. 2013; 154:375-87. [PubMed: 23239816]

25. Bartl J, Meyer A, Brendler S, Riederer P, Grünblatt E. Different effects of soluble and aggregated amyloid beta42 on gene/protein expression and enzyme activity involved in insulin and APP pathways. J Neural Transm. 2013; 120:113-20. [PubMed: 22782687]

26. Nalivaeva NN, Beckett C, Belyaev ND, Turner AJ. Are amyloid-degrading enzymes viable therapeutic targets in Alzheimer's disease? J Neurochem. 2012; 120(Suppl 1):167-85. [PubMed: 22122230]

27. Candeias E, Duarte AI, Carvalho C, et al. The impairment of insulin signaling in Alzheimer's disease. IUBMB Life. 2012; 64:951-7. [PubMed: 23129399]

28. Correia SC, Santos RX, Carvalho C, et al. Insulin signaling, glucose metabolism and mitochondria: major players in Alzheimer's disease and diabetes interrelation. Brain Res. 2012; 1441:64-78. [PubMed: 22290178]

29. Sonnen JA, Larson EB, Crane PK, et al. Pathological correlates of dementia in a longitudinal, population-based sample of aging. Ann Neurol. 2007; 62:406-13. [PubMed: 17879383] 


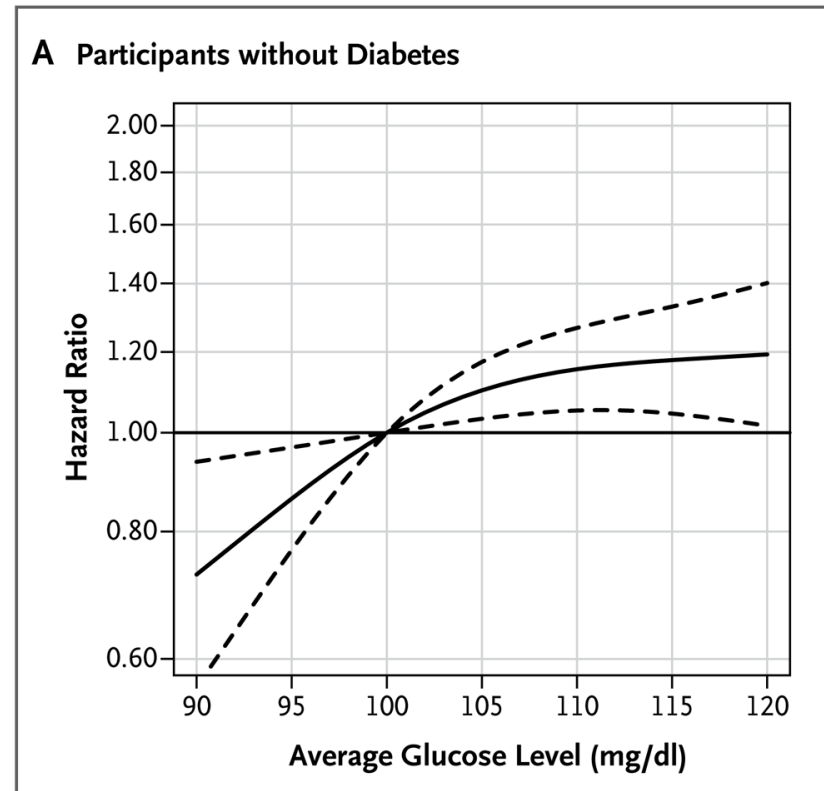

\section{B Participants with Diabetes}

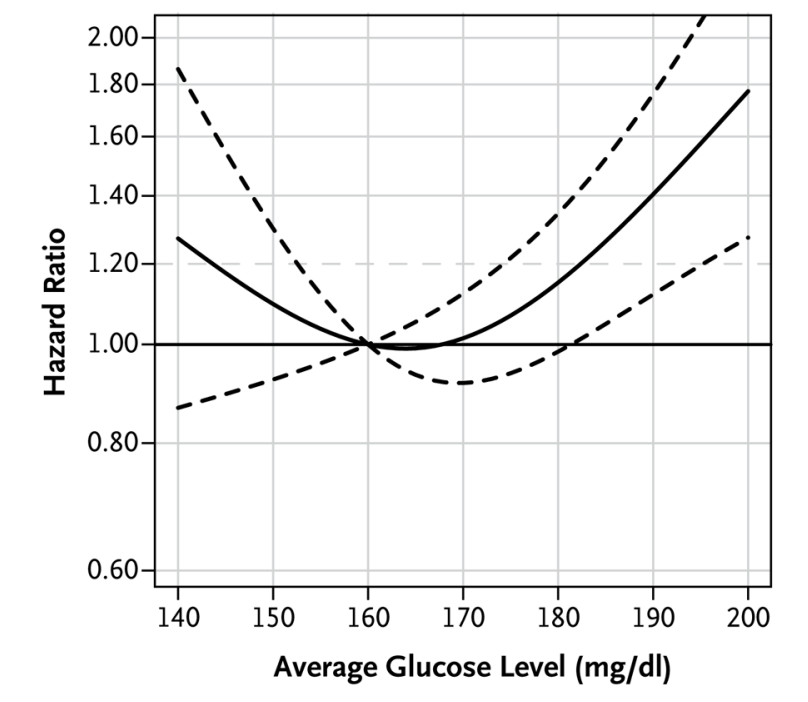

Figure 1. Risk of Incident Dementia Associated with the Average Glucose Level during the Preceding 5 Years, According to the Presence or Absence of Diabetes

Solid curves represent estimates of the hazard ratios for the risk of incident dementia across average glucose levels relative to a reference level of $100 \mathrm{mg}$ per deciliter for participants without diabetes (Panel A) and $160 \mathrm{mg}$ per deciliter for participants with diabetes (Panel B). The dashed lines represent pointwise $95 \%$ confidence intervals. To convert the values for glucose to millimoles per liter, multiply by 0.05551 . 


\section{Table 1}

Baseline Characteristics of the Study Participants.

\begin{tabular}{|c|c|c|}
\hline Characteristic & Participants with Diabetes $(\mathrm{N}=\mathbf{2 3 2})$ & $\begin{array}{l}\text { Participants without Diabetes }(\mathrm{N}= \\
\qquad 1835)\end{array}$ \\
\hline Member of original study cohort, $1994-1996$ — no. (\%) & $157(67.7)$ & $1344(73.2)$ \\
\hline \multicolumn{3}{|l|}{ Age $-\mathrm{yr}$} \\
\hline Median & 74 & 76 \\
\hline Interquartile range & $71-78$ & $71-81$ \\
\hline Female sex - no. $(\%)$ & $120(51.7)$ & $1108(60.4)$ \\
\hline \multicolumn{3}{|l|}{ Race - no. $(\%)^{*}$} \\
\hline White & $190(81.9)$ & $1673(91.2)$ \\
\hline Black & $28(12.1)$ & $72(3.9)$ \\
\hline Asian & $9(3.9)$ & $58(3.2)$ \\
\hline Other & $5(2.2)$ & $32(1.7)$ \\
\hline Education beyond high school — no. (\%) & $121(52.2)$ & $1122(61.1)$ \\
\hline Apolipoprotein E $\varepsilon 4$ allele - no. $(\%)^{\dagger}$ & $45(22.2)$ & $416(25.8)$ \\
\hline Atrial fibrillation - no. $(\%)$ & $32(13.8)$ & $201(11.0)$ \\
\hline Treated for hypertension - no. $(\%)$ & $189(81.5)$ & $1248(68.0)$ \\
\hline \multicolumn{3}{|l|}{ Mean blood pressure $-\mathrm{mm} \mathrm{Hg}$} \\
\hline \multicolumn{3}{|l|}{ Systolic } \\
\hline Median & 143 & 139 \\
\hline Interquartile range & $129-159$ & $126-155$ \\
\hline \multicolumn{3}{|l|}{ Diastolic ${ }^{\ddagger}$} \\
\hline Median & 73 & 75 \\
\hline Interquartile range & $66-80$ & $68-82$ \\
\hline Coronary artery disease - no. $(\%)^{\S}$ & $76(32.8)$ & $434(23.8)$ \\
\hline Cerebrovascular disease - no. $(\%)^{I l}$ & $36(15.7)$ & $207(11.3)$ \\
\hline Congestive heart failure - no. $(\%) \|$ & $15(6.5)$ & $89(4.9)$ \\
\hline Regular exercise - no. $(\%)^{* *}$ & $162(69.8)$ & $1300(70.8)$ \\
\hline \multicolumn{3}{|l|}{ Smoking status - no. $(\%)^{\dagger \dagger}$} \\
\hline Current smoker & $6(2.6)$ & $98(5.3)$ \\
\hline Former smoker & $125(53.9)$ & $853(46.5)$ \\
\hline Never smoked & $101(43.5)$ & $883(48.1)$ \\
\hline Self-rated health fair or poor - no. (\%) & $80(34.5)$ & $344(18.7)$ \\
\hline \multicolumn{3}{|l|}{ Race was self-reported. } \\
\hline
\end{tabular}


${ }^{I}$ Data on cerebrovascular disease were missing for 3 people with diabetes $(1.3 \%)$ and 9 people without diabetes $(0.5 \%)$.

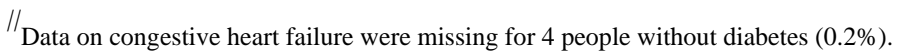

**

Regular exercise was defined as 3 or more "activity days" per week, defined as days in which at least 15 minutes of exercise such as walking, bicycling, or swimming was performed. See the Supplementary Appendix for further details.

${ }^{\dagger \dagger}$ Data on smoking were missing for 1 person without diabetes $(0.1 \%)$. 
Table 2

Risk of Incident Dementia Associated with Average Glucose Level over the Preceding 5 Years among Participants without Diabetes and Those with Diabetes.

\begin{tabular}{|lc|}
\hline Average Glucose Level & Hazard Ratio for Dementia (95\% CI) \\
\hline Participants without diabetes & \\
\hline $95 \mathrm{mg} / \mathrm{dl}$ & $0.86(0.77-0.97)$ \\
\hline $100 \mathrm{mg} / \mathrm{dl}$ & 1.00 \\
\hline $105 \mathrm{mg} / \mathrm{dl}$ & $1.10(1.03-1.17)$ \\
\hline $110 \mathrm{mg} / \mathrm{dl}$ & $1.15(1.05-1.27)$ \\
\hline $115 \mathrm{mg} / \mathrm{dl}$ & $1.18(1.04-1.33)$ \\
\hline $\mathrm{P} \mathrm{value}$ & 0.01 \\
\hline Participants with diabetes & \\
\hline $150 \mathrm{mg} / \mathrm{dl}$ & $1.10(0.92-1.30)$ \\
\hline $160 \mathrm{mg} / \mathrm{dl}$ & 1.00 \\
\hline $170 \mathrm{mg} / \mathrm{dl}$ & $1.01(0.92-1.12)$ \\
\hline $180 \mathrm{mg} / \mathrm{dl}$ & $1.15(0.98-1.34)$ \\
\hline $190 \mathrm{mg} / \mathrm{dl}$ & $1.40(1.12-1.76)$ \\
\hline $\mathrm{P} \mathrm{value}$ & 0.002 \\
\hline
\end{tabular}

* Estimates were adjusted for age at study entry, study cohort (original cohort enrolled in 1994 through 1996 versus expansion cohort enrolled in 2000 through 2002), sex, educational level, and time-varying measures of exercise level, average systolic and diastolic blood pressure, and status with respect to coronary artery disease, cerebrovascular disease, atrial fibrillation, treatment for hypertension, and smoking. The risk of dementia associated with different glucose levels was modeled with the use of natural cubic splines. The P values are based on omnibus tests of the composite hypothesis that all regression model parameters corresponding to the spline were equal to zero. As such, these P values reflect the significance for tests of the null hypothesis that there was no association between glucose level and risk of dementia, with distinct values for participants with diabetes and those without diabetes. To convert the values for glucose to millimoles per liter, multiply by 0.05551 . 
Table 3

Risk of Incident Dementia among Participants without and Those with Diabetes, According to Glucose Values Averaged over the Preceding 5 Years and the Period between 5 and 8 Years Earlier.*

\begin{tabular}{|c|c|}
\hline Average Glucose Level & Hazard Ratio for Dementia (95\% CI) \\
\hline \multicolumn{2}{|c|}{ Participants without diabetes } \\
\hline \multicolumn{2}{|l|}{ Preceding $5 \mathrm{yr}$} \\
\hline $95 \mathrm{mg} / \mathrm{dl}$ & $0.88(077-1.00)$ \\
\hline $100 \mathrm{mg} / \mathrm{dl}$ & 1.00 \\
\hline $105 \mathrm{mg} / \mathrm{dl}$ & $1.09(1.01-1.17)$ \\
\hline $110 \mathrm{mg} / \mathrm{dl}$ & $1.14(1.01-1.27)$ \\
\hline $115 \mathrm{mg} / \mathrm{dl}$ & $1.16(1.00-1.35)$ \\
\hline$P$ value & 0.09 \\
\hline \multicolumn{2}{|c|}{ Between 5 and 8 yr earlier } \\
\hline $95 \mathrm{mg} / \mathrm{dl}$ & $0.94(0.81-1.08)$ \\
\hline $100 \mathrm{mg} / \mathrm{dl}$ & 1.00 \\
\hline $105 \mathrm{mg} / \mathrm{dl}$ & $1.03(0.95-1.10)$ \\
\hline $110 \mathrm{mg} / \mathrm{dl}$ & $1.02(0.91-1.15)$ \\
\hline $115 \mathrm{mg} / \mathrm{dl}$ & $1.01(0.85-1.20)$ \\
\hline$P$ value & 0.65 \\
\hline \multicolumn{2}{|l|}{ Participants with diabetes } \\
\hline \multicolumn{2}{|l|}{ Preceding $5 \mathrm{yr}$} \\
\hline $150 \mathrm{mg} / \mathrm{dl}$ & $1.15(0.94-1.42)$ \\
\hline $160 \mathrm{mg} / \mathrm{dl}$ & 1.00 \\
\hline $170 \mathrm{mg} / \mathrm{dl}$ & $0.96(0.85-1.10)$ \\
\hline $180 \mathrm{mg} / \mathrm{dl}$ & $1.04(0.84-1.28)$ \\
\hline $190 \mathrm{mg} / \mathrm{dl}$ & $1.20(0.89-1.62)$ \\
\hline$P$ value & 0.06 \\
\hline \multicolumn{2}{|c|}{ Between 5 and 8 yr earlier } \\
\hline $150 \mathrm{mg} / \mathrm{dl}$ & $0.92(0.79-1.07)$ \\
\hline $160 \mathrm{mg} / \mathrm{dl}$ & 1.00 \\
\hline $170 \mathrm{mg} / \mathrm{dl}$ & $1.06(0.96-1.18)$ \\
\hline $180 \mathrm{mg} / \mathrm{dl}$ & $1.10(0.91-1.34)$ \\
\hline $190 \mathrm{mg} / \mathrm{dl}$ & $1.13(0.85-1.50)$ \\
\hline$P$ value & 0.52 \\
\hline
\end{tabular}

* Estimates were adjusted for age at study entry, study cohort, sex, educational level, time-varying measures of exercise level, average systolic and diastolic blood pressure, and status with respect to coronary artery disease, cerebrovascular disease, atrial fibrillation, treatment for hypertension, and smoking. The associations between glucose levels and the risk of dementia were modeled with the use of natural cubic splines, with separate splines for distant levels (5 to 8 years) and recent levels (up to 5 years). The $\mathrm{P}$ values are based on omnibus tests of the composite hypothesis that all regression model parameters corresponding to the spline were equal to zero. As such, these P values reflect the significance for tests of the null hypothesis that there was no association between glucose level and risk of dementia, with distinct values for participants with diabetes and those without diabetes. 